\title{
Cluster Structure and Reactions: Gaining Insights into Catalytic Processes
}

\author{
A. W. Castleman Jr.
}

Received: 18 July 2011/Accepted: 18 July 2011/Published online: 9 August 2011

(C) The Author(s) 2011. This article is published with open access at Springerlink.com

\begin{abstract}
To many researchers outside the field of cluster science it may come as a surprise that much can be learned of its relevance to catalysis, even restricting the discussion to ionized systems. This perspective is largely focused on catalytic oxidation reactions in which oxygen radical centers on transition metal oxides play a dominant role. The objective is to present how fundamental insights into reaction mechanisms can be gained through employing alternative approaches that complement rather than supersede more conventional methods in $t$ he field of catalysis. In view of the well acknowledged role of defect centers in effecting reactivity, and the preponderance of recent papers presenting evidence of the importance of charged sites, the need/desire to conduct repetitive experiments is clear. Presented herein are approaches using clusters to accomplish this in order to unravel fundamental catalytic reaction mechanisms, and to use identified superatoms and the concepts of element mimics to tailor catalysts with desired functionality.
\end{abstract}

Keywords Heterogeneous catalysis - Catalysis · Gas-phase kinetics Elementary kinetics · Reaction intermediates $\cdot$ Superatoms

\section{Introduction}

Considering the global need for new sources of energy, enhanced methods of pollution abatement, advanced approaches to the production of fine chemicals, sensors for

\footnotetext{
A. W. Castleman Jr. ( $\square)$

Departments of Chemistry and Physics, The Pennsylvania State University, University Park, PA 16802, USA

e-mail: awc@psu.edu
}

the detection of harmful materials, as well as new methods of evaluating medical and biological issues, it is clear that catalysis, which impacts all of these, is one of the most important subjects for scientific investigation [1]. In view of the large diversity of reactions and accompanying physical phenomena involved, unraveling the fundamentals of catalytic processes requires a wide range of studies [2]. Clearly no single approach is sufficient to elucidate all of the issues which arise in unraveling catalytic processes, and advances in the subject benefit from well devised investigations of many types [3-6].

One valuable approach employs the use of clusters whose chemistry can be used to follow the course of reactions influenced by various reactive centers/defect sites, and the present invited perspective focuses on past developments and future prospects in this area [2, 5, 7-10]. While acquiring reproducible defect sites for the purpose of elucidating their influence on the course of catalytic reactions is an arduous task, it is a relatively straight forward procedure to recreate and conduct repetitive studies on model clusters which mimic specific reaction centers. There is growing evidence that sites of differing charge density can greatly influence reactions and the effect of these is identifiable through a study of mass selected cluster ions [7-12]. Comparison of the reactivity of anionic and cationic clusters can therefore provide insight into the importance of an accumulation or deficiency of electron density on the reactivity of catalytic materials.

There is increasing interest in the field of nanocatalysis which can be easily modeled through the use of clusters, both in terms of the operative catalytic reaction mechanisms as well as the production of the catalysts themselves [2-4]. Moreover gas-phase cluster experiments allow the fundamental reactive behavior of catalytic materials to be studied in an environment that enables the influence of 
such factors as size, stoichiometry, as well as ionic charge state on cluster reactivity to be determined with atomiclevel precision. For nanocatalysis this is particularly relevant since the reactive properties have been known to change dramatically with the addition or removal of even a single atom [7-12].

\section{Elucidating Mechanisms of Catalytic Reactions}

It is clearly a daunting task to design effective catalysts based solely on fundamental principles and, prior to the last few decades, much of the earlier successes in this endeavor depended on empirical tests employing materials of known effectiveness for promoting selective classes of reactions. The available methods began to change as progress was made in the field of surface science, first in the area of UHV and subsequently under more realistic reaction conditions $[2,3]$. In recent years increasing focus has turned to basic studies with various modern techniques such as surface harmonic generation, scanning tunneling microscopy, ambient-pressure X-ray photoelectron spectroscopy, and X-ray absorption spectroscopies, for example [4]. One of the main problems has been identifying specific reaction sites as these frequently involve defects which are difficult to generate, characterize and reproduce.

In recent years cluster science has begun to make significant inroads into this area, making it possible to generate species that can emulate certain reaction centers. For example, in various studies we found that clusters of selected sizes can serve as surface sites, where their structure may have geometries akin to steps, ledges, or corners, with characteristic accompanying charge densities [7-10]. Certain cluster structures such as those shown for example in Fig. 1, can serve as model surface sites. These can be readily formed using standard methods from cluster science $[13,14]$.

During the course of conducting studies having particular focus on work related to cluster models of catalytic activity, we obtained findings which showed the dramatic effect that can arise upon making minor compositional changes in a cluster. The Castleman group has had a long standing interest in the application of cluster science for unraveling certain catalytic mechanisms such as oxygen transfer, employing specific clusters as model surface sites $[8,9]$. One example is seen from a consideration of the dehydration reaction of 1,3-butadiene initiated by vanadium oxide clusters of particular stoichiometries; see Fig. 2. Among the many clusters of varying vanadium to oxygen ratios which have been studied, only $\mathrm{V}_{3} \mathrm{O}_{7}{ }^{+}$and $\mathrm{V}_{5} \mathrm{O}_{12}{ }^{+}$effected such a specific chemical transformation.

\section{Clusters}

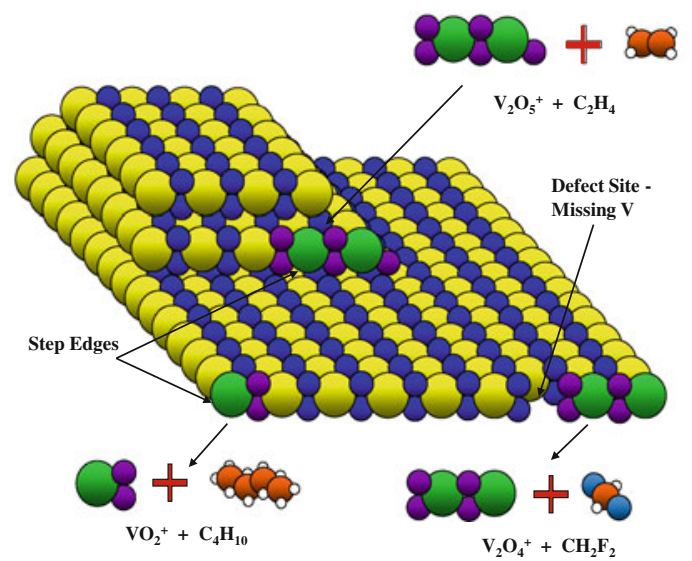

Fig. 1 Steps/ledges/corners: reactive centers mimicked by clusters (adapted from [10])

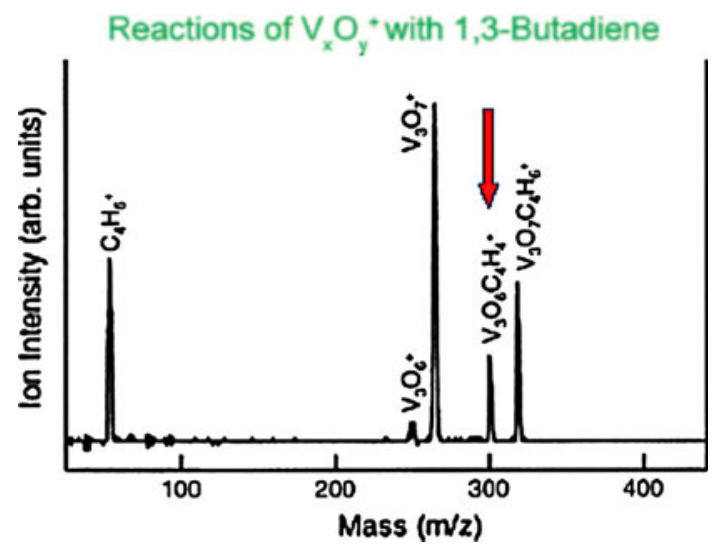

Fig. 2 Reaction of $\mathrm{V}_{x} \mathrm{O}_{y}^{+}$clusters with 1,3 butadiene. Only $\mathrm{V}_{3} \mathrm{O}_{7}{ }^{+}$and $\mathrm{V}_{5} \mathrm{O}_{12}{ }^{+}$display a dehydration reactive channel [15]

One example of the success made in identifying mechanisms for oxygen transfer reactions involved the formation of acetaldehyde from ethylene interacting with vanadium oxides as the reaction sites. See Fig. 3. Significantly, among a wide range of clusters studied, only $\mathrm{V}_{2} \mathrm{O}_{5}{ }^{+}$ and $\mathrm{V}_{4} \mathrm{O}_{10}{ }^{+}$were found to function in effecting this reactive transformation. This is particularly interesting as $2: 5$ is the metal to oxygen composition of bulk catalysts that yield a similar reaction product.

It is well accepted that cluster experiments provide insight into the influence of composition, geometry and size on reactive behavior. In combination with theory, the enhanced reactivity of these cluster species was traced to the presence of an oxygen centered radical on a metal atom, and its influence on the energy barrier $[15,16]$. See the calculated reaction profile in Fig. 4. 
Fig. 3 Branching ratios for reactions of vanadium oxide cluster cations with ethylene. Note that the formation of $\mathrm{C}_{2} \mathrm{H}_{4} \mathrm{O}$ occurs only for $\mathrm{V}_{2} \mathrm{O}_{4}{ }^{+}$ and $\mathrm{V}_{4} \mathrm{O}_{10}{ }^{+}$; red squares (adapted from [10])

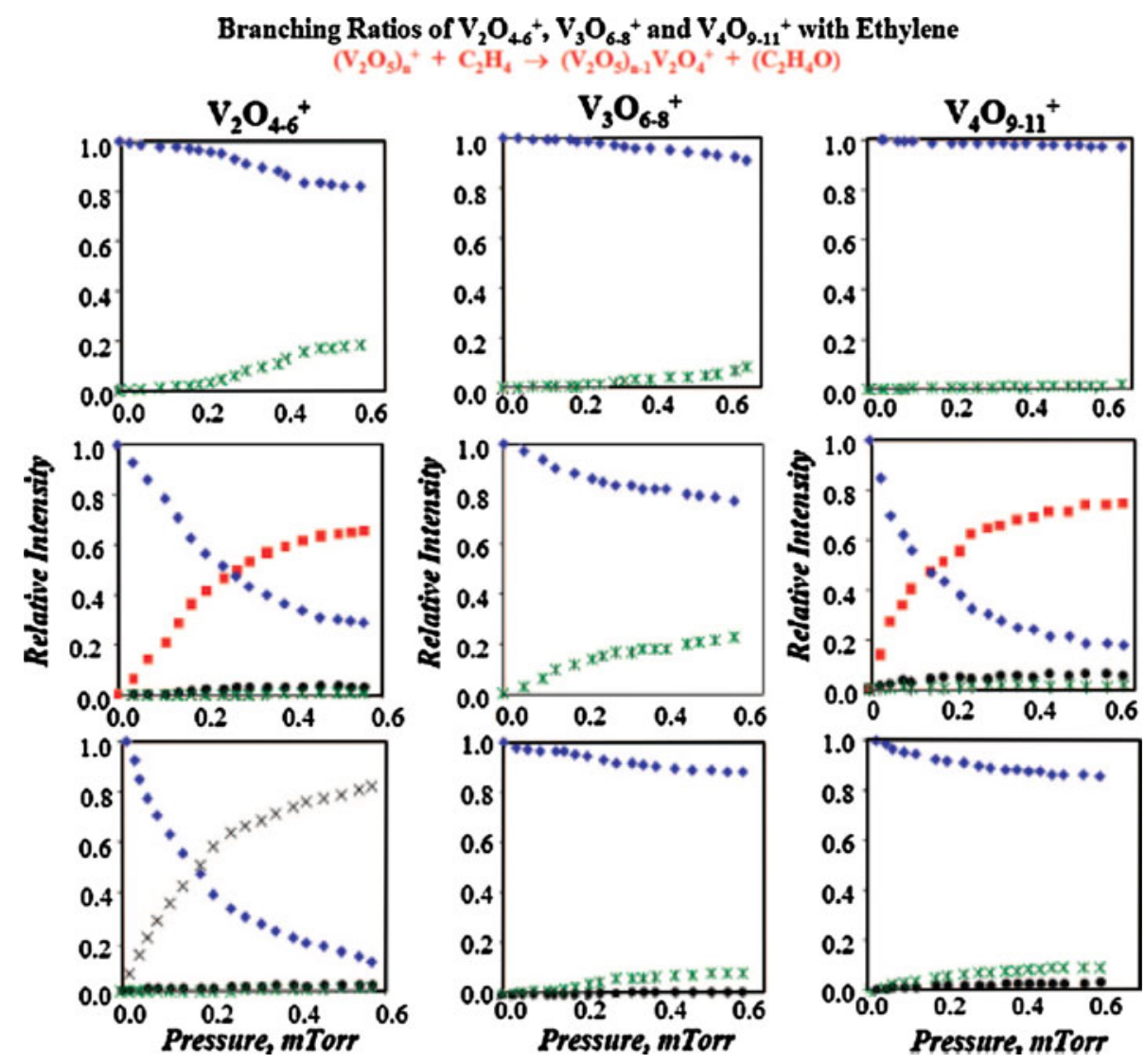

Oxidation of Ethylene by Vanadium Oxide

- Vanadium oxide catalyzes the selective oxidation of hydrocarbons on the industrial scale

- In laboratory experiments, the clusters $\left(\mathrm{V}_{2} \mathrm{O}_{5}\right)_{12}{ }^{+}$selectively oxidize ethylene

- Oxidation occurs by a radical cation mechanism
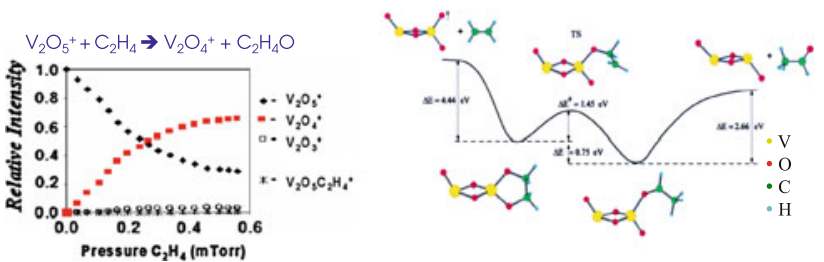

Fig. $4 \mathrm{~V}_{x} \mathrm{O}_{y}^{+}-\mathrm{C}_{2} \mathrm{H}_{4}$ reaction profile involving a radical oxygen cation center (adapted from [17])

As mentioned above, one other issue that sometimes arises in comparing the findings of cluster studies with bulk catalytic investigations is the matter of cluster charge. Earlier debates raised issues such as questions whether charged clusters were suitable catalyst mimics; the large number of recently reported findings that charged centers play a role in the functioning of many classes of catalytic reactions have put these concerns to rest. In fact it is becoming increasingly realized that a large variety of heterogeneous catalysts function due to the presence of defects having large local charge-density centers [18-36]. And, in the context of our own findings, this issue was also settled in the course of comparing cluster reactions for a variety of classes of reactions with the findings of known catalysts. Although the rates of reactions involving isolated charge centers may differ from those of a bulk material, in many cases the reaction mechanisms are similar [15-17, 37-55].

Further evidence that cluster studies can provide insights into broad classes of reaction mechanisms is seen from examples shown in Fig 5. The finding of a similarity in chemical behavior of numerous clusters compared to those of various bulk catalysts, is striking.

That there is often some close correspondence between cluster reactions and bulk catalytic processes is not completely surprising. It is a relatively straight forward assumption to conceive of increasingly larger clusters asymptotically approaching properties corresponding to those of surfaces, albeit in the cluster case ones suspended in a gas. Depending on the reactive domain size, we can expect relatively small differences with cluster size and we expect the main differences to be reflected in the operative dynamical cross sections. Therefore similar mechanisms should obtain for reactions involving either large clusters or analogous surface sites, whereupon the study of large 
Fig. 5 Similarities in chemical behavior between various clusters (Column 1) and bulk catalysts (Column 3)

\section{Correlation Between Gas and Condensed Phase}

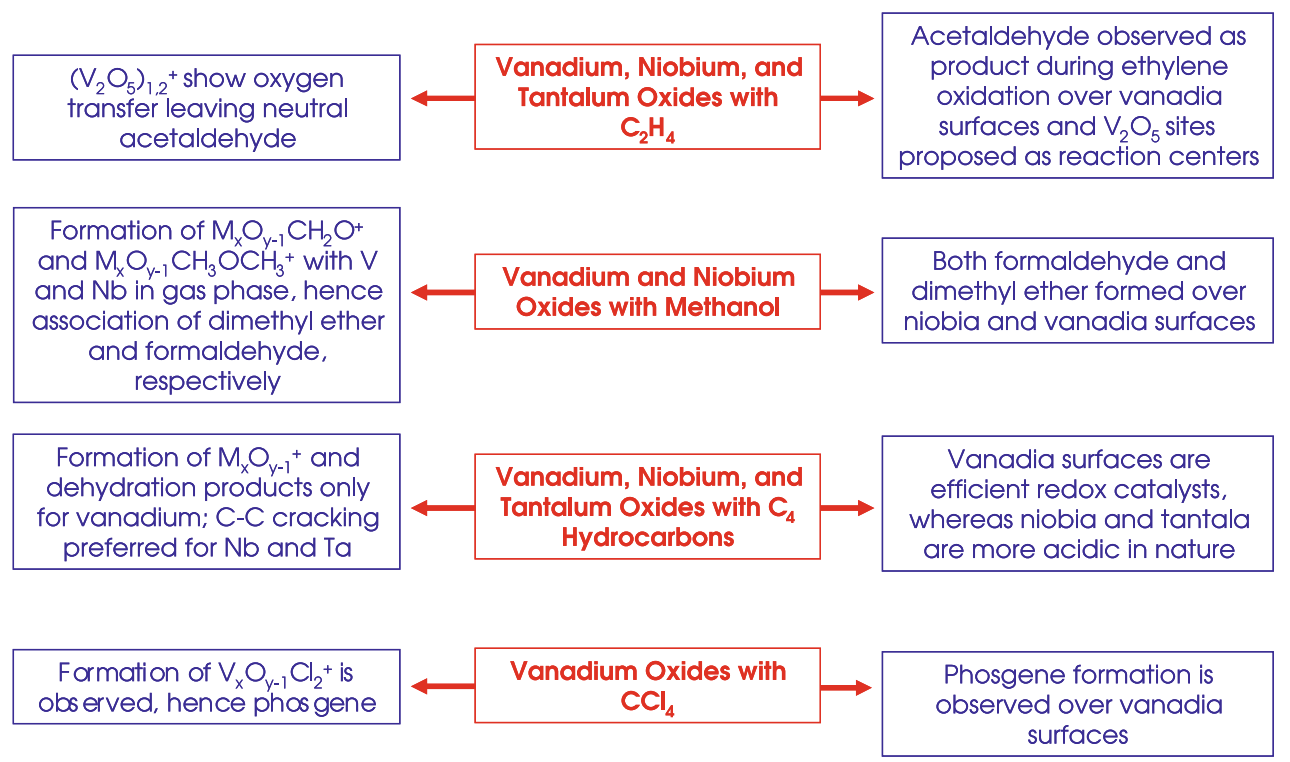

clusters should enable fundamental insights into the related chemistry of the oxides to be acquired.

As an extension of these ideas, we undertook an investigation of reactions of stoichiometric $\mathrm{ZrO}_{2}$ cationic clusters, interacting with a variety of small molecules including CO, ethylene and acetylene [56]. The findings revealed the presence of an active site consisting of a radical oxygen center that can be transferred, thereupon readily oxidizing these species.

In contrast to the cationic species which were found to be highly active toward the oxidation of all three molecules, anionic clusters of indicated stoichiometry corresponding to $\left(\mathrm{Zr}_{x} \mathrm{O}_{2 x+1}\right)^{-}(x=1-4)$ (that can be conceptionally formed by adding one oxygen atom with a full octet of valence electrons $\left(\mathrm{O}^{2-}\right)$ ) were also found to oxidize carbon monoxide, but only strongly associate acetylene rather than oxidize it, and weakly associate ethylene [57].

Theoretical investigations indicate that a critical hydrogen transfer step necessary for the oxidation of ethylene and acetylene at metal oxide clusters containing radical oxygen centers is energetically favorable for cationic clusters but unfavorable for the corresponding anionic species as found experimentally. The reason is traced to the nature of an interacting electrostatic potential of the cluster which reveals that in the case of cations, a favorable interaction with nucleophilic molecules takes place over the whole surface of the $\left(\mathrm{ZrO}_{2}\right)_{x}^{+}(x=1-4)$ clusters, while a restricted interaction of ethylene and acetylene with the less coordinated zirconium atom is involved in the case of the anionic $\left(\mathrm{Zr}_{x} \mathrm{O}_{2 x+1}\right)^{-}(x=1-4)$ species. See Fig. 6. In the case of $\mathrm{C}_{2} \mathrm{H}_{2}$, for example, the association with $\mathrm{Zr}_{2} \mathrm{O}_{5}{ }^{-}$ occurs in two configurations: at the oxygen radical center and at the less coordinated zirconium atom. The initial encounter complex is about $2 \mathrm{eV}$ more stable than the separated reactant. Also the oxygen radical is localized on one of the oxygen atoms on the opposite side of the cluster to where the acetylene associates. For reaction to occur, considerable rearrangement is required and a substantial barrier is involved in breaking the zirconium-carbon bond and migration of the oxygen atom. Therefore, in spite of the common presence of a radical oxygen center in species with specific anionic and cationic stoichiometries, the extent to which various classes of reactions are promoted is significantly influenced by charge state/local charge density.

That the reactions are catalytic in nature was determined for the $\left(\mathrm{Zr}_{x} \mathrm{O}_{2 x}\right)^{+}(x=1-4)$ series of cationic clusters where it was shown that the reactant ion could be regenerated by reacting oxygen deficient clusters with a strong oxidizer. See Fig. 7.

This work demonstrates that not only cationic species, as shown in previous work, but also anionic clusters may

\section{Calculated Molecular Electrostatic Potential (MEP)}

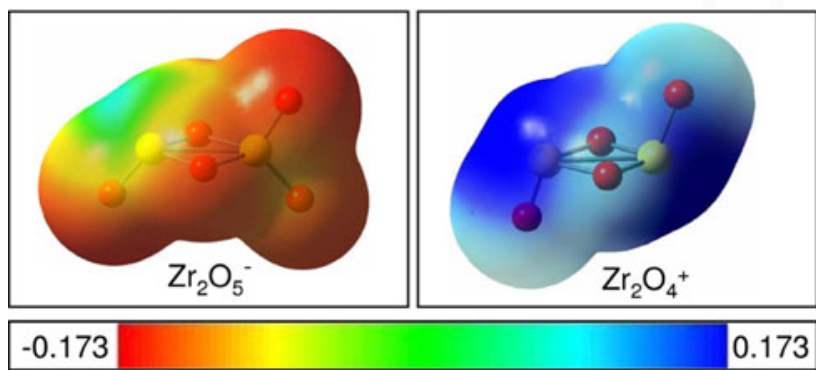

Fig. 6 Surface electrostatic potential [56] 
Full Catalytic Cycle for Oxidation of CO, $\mathrm{C}_{2} \mathrm{H}_{4}$ and $\mathrm{C}_{2} \mathrm{H}_{2}$

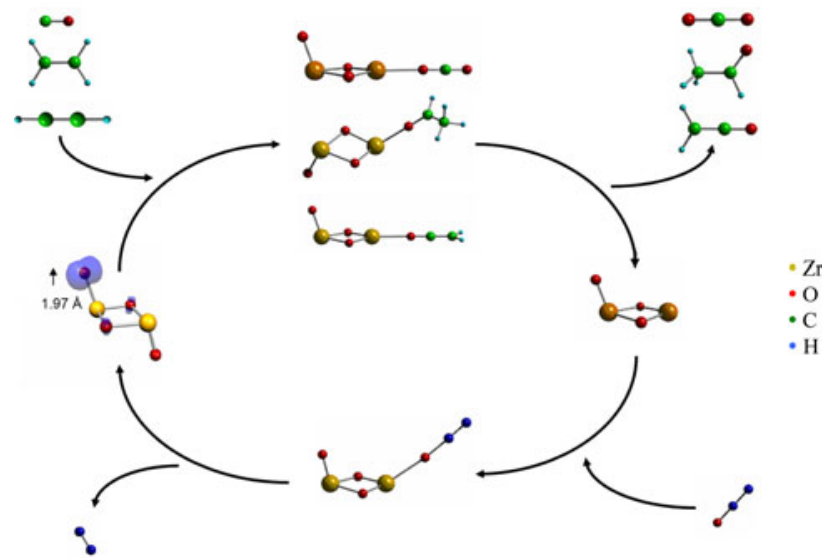

Fig. 7 Full catalytic cycle obtained for the reaction of $\mathrm{Zr}_{2} \mathrm{O}_{4}{ }^{+}$with $\mathrm{CO}, \mathrm{C}_{2} \mathrm{H}_{4}$, and $\mathrm{C}_{2} \mathrm{H}_{2}$ and regeneration of the reacted cation with $\mathrm{N}_{2} \mathrm{O}$ [57]

promote multiple cycles of carbon monoxide oxidation, for example [56, 57]. The findings reveal the prospect of being able to tailor the characteristics of a catalyst via doping a system to control the charge density and hence reactivity.

Another example of the value of cluster studies in shedding light into mechanisms of individual reaction steps pertains to the role of small gold clusters in effecting the oxidation of $\mathrm{CO}$. Prior to the experimental investigations of Haruta [58], gold was considered to be inert. In recent years, numerous experimental and theoretical studies have revealed the contrary, prompting extensive work to elucidate the mechanisms involved [59-67]. Important remaining questions included: Do small gold clusters contribute to the presence of $\mathrm{O}$-atoms sufficient to promote oxidation of $\mathrm{CO}$; and what is the influence of charge accumulation or deficiency on the reactivity? Forming small cationic and anionic clusters is quite facilely accomplished, whereupon such questions can be readily addressed. For example, as shown for anionic gold oxides in Fig. 8, clusters comprised of peripheral and bridging $\mathrm{O}$ sites, as well as the presence of molecular $\mathrm{O}_{2}$ can be formed and investigated, answering the questions raised above as well as others. Cluster studies revealed that the formation of $\mathrm{O}$ atoms is necessary, though not sufficient as barriers to transfer can still impede the oxidation reaction.

The results obtained provide further aspects of the insights that can be gained from cluster experiments [7-10].

\section{An Approach to Designing Nanoscale Catalysts}

Studying individual clusters of selected size provides the opportunity to investigate factors governing physical and

\section{Peripheral Oxygen}

- Eley-Rideal-like Mechanism

- CO attacks O forming complex (I) - CO weakly bound to O

- Charge transfers to CO forming complex (II)

- CO strongly bound to 0

- Two possible channels from complex (II)

- Au-O bond rupture followed by $\mathrm{Au}-\mathrm{C}$ bond formation, complex (III)

- Rotation of CO out of molecular plane

- $\mathrm{CO}_{2}$ departs transferring charge back

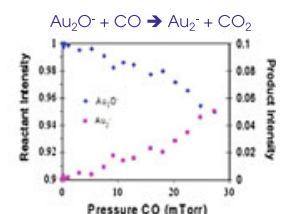
to Au

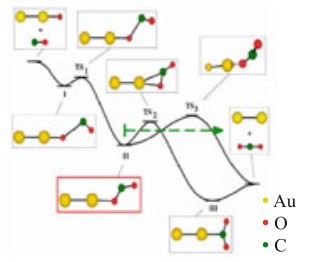

Is $\mathrm{O}_{2}$ Dissociation Sufficient to Enable CO Oxidation?

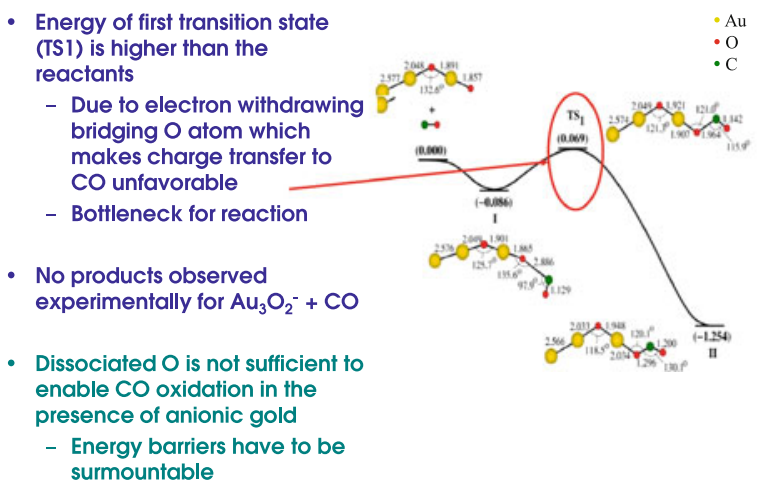

Fig. 8 Oxidation sites for gold-oxygen cluster systems [43]

chemical behavior such as size, composition, and charge state and electron density. With well designed studies, clusters can serve as tractable models for unraveling mechanisms of catalytic reactions on the one hand and yield information of value in designing nanocatalysts with specific reactivity and/or selectivity on the other. Our own work has brought out these aspects in investigations of numerous classes of reactions [7-10].

In addition to questions of selectivity, when applications are considered, concerns about costs of materials often arise. In this context fundamental studies which serve to identify mechanisms and hence, also point to possible substitute materials, play an important role in choice. Important are guiding principles to follow in designing an alternative material through the use of the concept of element mimics which we have pioneered. If the cluster functions as a viable substitute, "its chemistry" should bear some resemblance to that of the corresponding element. This raises the prospect that one approach would be to look for related electronic states, hence providing a way to quantify a concept we considered as an extension of Mulliken's unified atom [68, 69], subsequently termed a 
Fig. 9 Energy level diagrams, binding energy (BE) spectra, and raw photoelectron images for $\mathrm{Pt}^{-}$and $\mathrm{WC}^{-}$at a photon energy of $2.33 \mathrm{eV}(532 \mathrm{~nm})$. The inset to the $\mathrm{Pt}^{-}$binding energy spectrum displays weaker intensity transitions from anion excited states. Isosurface plots of the highest occupied $16 \sigma$ and $4 \delta$ molecular orbitals appear as insets to the $\mathrm{WC}^{-}$binding energy spectrum. See details in [51]

Fig. 10 Energy level diagrams, binding energy (BE) spectra, and raw photoelectron images for $\mathrm{Ni}^{-}$and $\mathrm{TiO}^{-}$at a photon energy of $2.33 \mathrm{eV}(532 \mathrm{~nm})$. Surface plots of the highest occupied $9 \sigma$ and $1 \delta$ molecular orbitals from ab initio

calculations appear in the inset of the binding energy spectrum of $\mathrm{TiO}^{-}$. Note their resemblance to the associated $3 \mathrm{~d}$ and $4 \mathrm{~s}$ atomic orbitals of Ni. See [51] for details
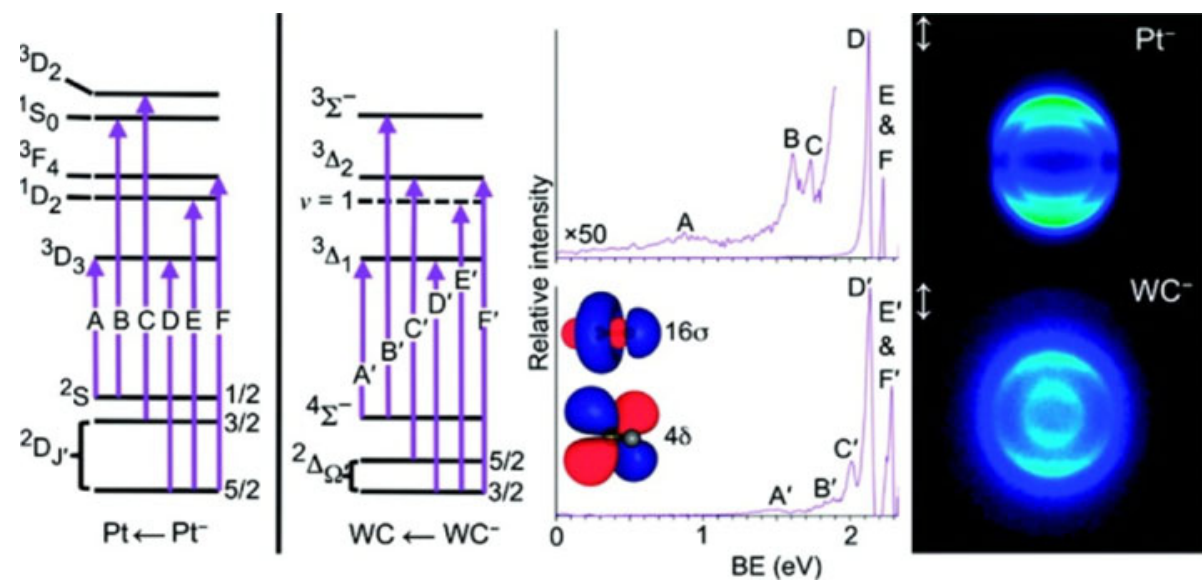

(a)
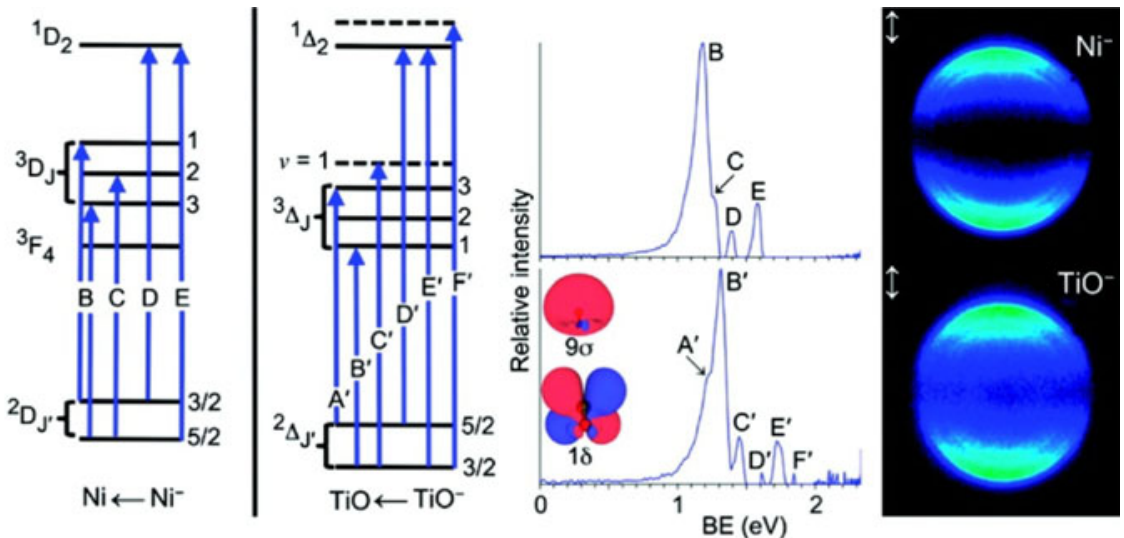

(b)
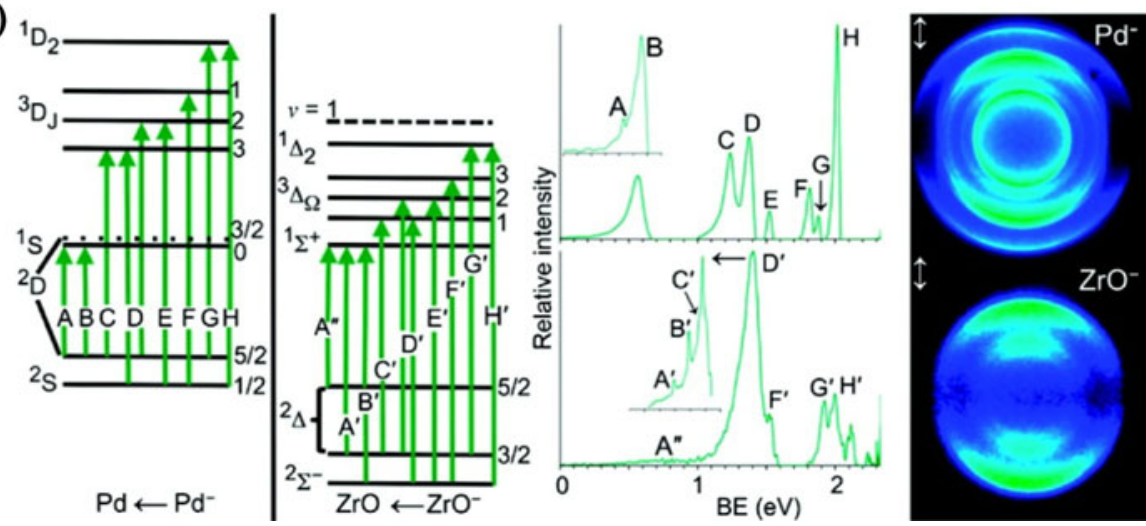

"superatom" in the case of clusters [70]. It was soon realized that element cluster mimics are not only of value in identifying reaction mechanisms, but in addition may provide a valuable tool to tailor the design of new nanoscale materials having selected properties [71].

It has been found that even species with differing compositions but having similar structural arrangements (hence displaying similar electronic character) can be quantitatively quite similar. This is seen from comparison of the nearly identical vertical detachment energies and electron affinities found for a series of large clusters showing the prospect of being able to extend the concepts to larger (nanocatalytic) systems.

It is a known principle in chemistry that compounds having nearly the same electronic character will yield species with somewhat similar properties. However, "isoelectronic" implies similar structure as well as valence electrons [72]; lacking similar structural geometry, a term such as "isovalency" may be more appropriate. Hints that certain cluster compounds with similar electronic character to various elements might display similar chemistry to an element was suggested by early studies of Boudart and 
Fig. 11 Energy level diagrams, BE spectra, and raw photoelectron images for $\mathrm{Pd}^{-}$ and $\mathrm{ZrO}^{-}$at a photon energy of $2.33 \mathrm{eV}(532 \mathrm{~nm})$. The insets to the BE spectra display higherresolution reconstruction slices of the indicated energy regions. Peak $C^{\prime}$ and the ${ }^{3} \Delta_{1} \leftarrow{ }^{2} \Sigma^{-}$ component of $\mathrm{D}^{\prime}$ appear as unresolved shoulders to more intense transitions. See [51]. The lower diagrams are the branching ratios for the two systems, showing similar reactivities for $\mathrm{Pd}$ and $\mathrm{ZrO}$ [76]

\section{Comparison of Isovalent Pd and ZrO}

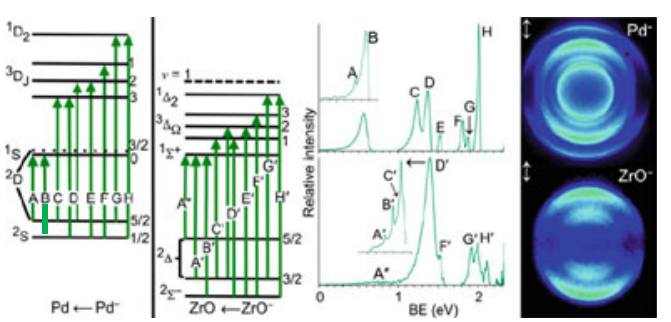

Reaction of $\mathrm{Pd}^{+}$and $\mathrm{ZrO}^{+}$with Ethane PdandZrOorbitals.

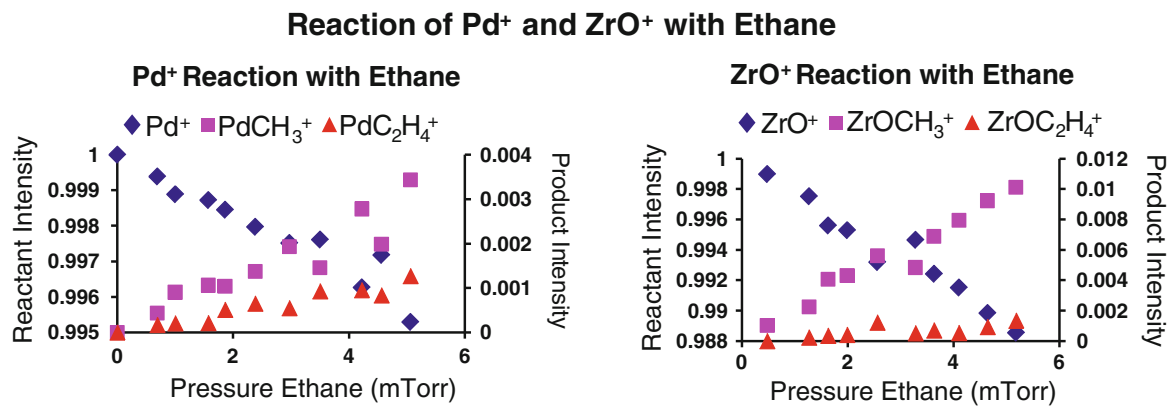

- Similar electronic transitions have been identified between

- Zr 2c/gram vs. Pd \$100/ gram

- Resemblance in the anisotropy reveals similar angular momentum character of the

co-workers [73] who, during the early 70s, reported that WC and platinum, which have somewhat similar electronic configurations, could both display some similar catalytic behavior. Considerations were based on the expected similar vertical electron detachment energies of WC and $\mathrm{Pt}$, and their electron affinity values, a fact that we experimentally established via photoelectron measurements [74].

Due to the more restrictive selection rules involved in evaluating electronic transitions via absorption spectroscopy, photoelectron spectroscopy results were considered more appropriate for evaluating the validity of various superatoms as element mimics. Employing the technique of velocity map imaging enabled us to quantify the electronically excited state characteristics of cluster element mimics, including their anisotropies which provide information on the symmetry of the orbitals from which the electrons are ejected. Extending these quantitative measurements to a variety of systems led us to similar findings of other promising element mimics [75, 76].

Although not fully rigorous, a first step in comparing the expected similarity of potential catalyst materials in terms of element mimic characteristics is to consider their electronic states. Here we give consideration to three systems where electronic states are the bases chosen.

First we consider platinum and tungsten carbide, species which have the same valence [74]. An energy level diagram for the systems is given for the two species along with images determined for the anisotropy parameters employing a velocity map imaging technique. See Fig. 9.

The images corresponding to the electron emissions from various orbitals are displayed. Evident is the fact that WC does reveal electronic transitions closely akin to those of $\mathrm{Pt}$, accounting for the fact that WC reveals similar surface catalytic behavior [28]. Although the spectra are not quantitatively identical, the similarities of the electronic excited states as well as the anisotropy parameters $(\beta)$ are evident. Evidence that this is not a mere coincidence in the $\mathrm{Pt} / \mathrm{WC}$ case is apparent by comparing spectra for other isovalent pairs such as $\mathrm{TiO}^{-}$, which reveals remarkable similarity [75] to that of $\mathrm{Ni}^{-}$, and similarly, $\mathrm{ZrO}^{-}$compares well with $\mathrm{Pd}^{-}$. Examples are shown in Figs. 10 and 11.

Even though mimics having similar electronic states as various elements have been found, a question regarding the similarity or equivalence of their reactive/catalytic behavior arises. To shed light on this possible issue, we commenced detailed study of a number of small organic molecules interacting with various cluster ions of equivalent valence. In this context particular attention was given to reactions of some palladium cation-clusters with small organic molecules such as ethane and propane, finding nearly identical behavior for chemical reactions of $\mathrm{Pd}$ and the mimic $\mathrm{ZrO}$, even for species of a differing (+1 vs. -1) charge state. See Fig. 11 which reveals $\mathrm{C}-\mathrm{C}$ bond scission and hydrogen abstraction. This unexpected, but promising behavior does still require further investigation for other systems. Nevertheless, the promise is also upheld so far by our recent results found for reactions of $\mathrm{ZrO}_{2}^{+}$yielding products analogous to those acquired with $\mathrm{PdO}^{+}$.

\section{Devising New Catalyst Materials}

In this perspective we have shown that under carefully chosen conditions, the study of cluster properties and 
Fig. 12 a Mixed metal neutral cluster mimic charged cluster reactions [53]. b The prospect of tailoring catalyst effectiveness via doping/mimicking charge state effects. Altering characteristics of catalytic materials via doping materials with elements of differing electron density to mimic charge effects (adapted from [53]) (a)

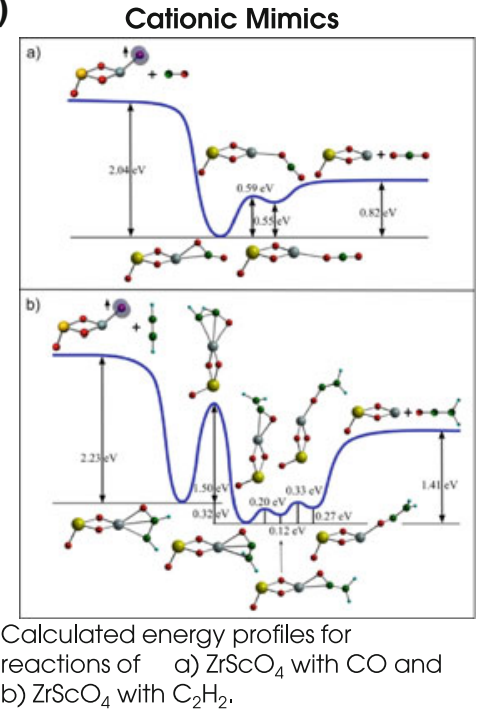

Anionic Mimics

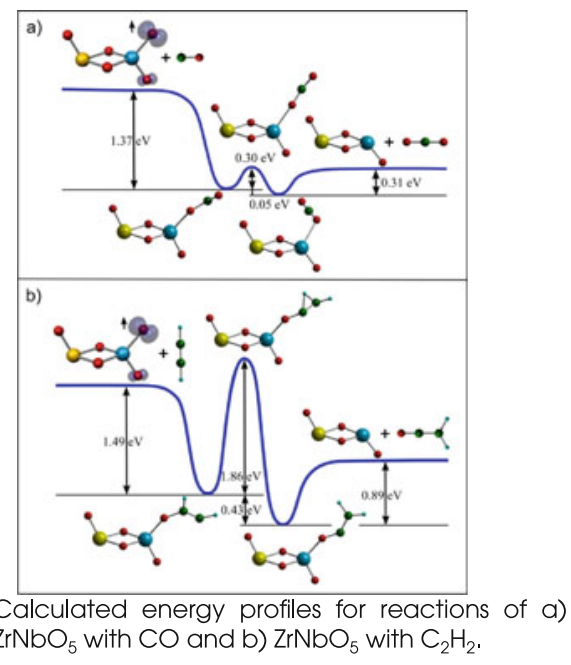

(b)

Generation of Radical Centers in Binary Neutral Metal Oxide Clusters for Catalytic Oxidation Reactions

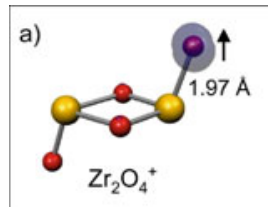

c)

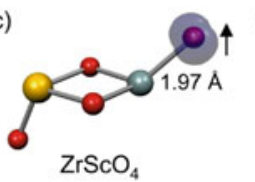

b)

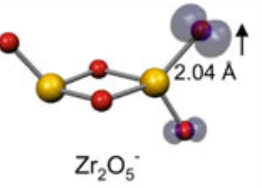

d)

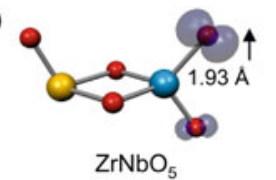

Calculated lowest energy structures for a) $\mathrm{Zr}_{2} \mathrm{O}_{4}{ }^{+}$b) $\mathrm{Zr}_{2} \mathrm{O}_{5}^{-}$c) $\mathrm{ZrScO}_{4}$ and d) $\mathrm{ZrNbO}_{5}$. The radical oxygen centers are indicated by an arrow. The gray isosurface indicates the localized spin density.

reactions can enable further understanding of the fundamentals of selected catalytic mechanisms at the molecular level. Additionally insights into potential superatom element mimics can be deduced from measurements of electronic states, suggesting the prospect that materials with desired functionality might be designed and constructed employing appropriate building blocks. Although materials formed via cluster assembly are usually composed of varying numbers of assemblies of the building blocks, and it is important that the individual clusters that provide the desired functionality do not coalesce; designing an approach to effectively impede this is currently one of the major challenges in the superatom field.

One can raise the issue of why there may be an advantage in materials formed via the assembly of element mimics rather than employing ones simply produced using the elements themselves. The key reason is that through an assembly process, it may be possible to acquire materials with more than a single functionality, for example, detection followed by destruction. Indeed, the prime objective of the studies presented here is to acquire the ability to tailor the chemical nature of superatom cluster building blocks for devising new nanoscale materials with desired selectivity. If one can attain the ability to form a material with certain chosen chemical characteristics that perform differently when perturbed, a wide variety of new avenues would be opened up. In some cases another potential motivation derives from cost considerations of mimics versus elements.

Until recently the jellium shell model has provided the main basis for conceiving the design of new superatoms. 
This has been overridden by the semi-quantitative concepts allowed by determinations of orbital symmetry and related asymmetry parameters identified through studies of velocity map imaging. Focusing on compositional effects, and particularly on the role of support materials is becoming a subject of increasing interest.

A recent example of how local compositional variations can substantially alter catalytic characteristics is seen from calculations of the generation of oxygen radical centers in binary metal oxide clusters [77]. The energetics and associated barriers in catalytic oxidation reactions have been shown to be readily altered in reactions of zirconium oxides with $\mathrm{C}_{2} \mathrm{H}_{2}$ and $\mathrm{CO}$ through partial substitution of $\mathrm{Sc}$ to acquire charge depletion or $\mathrm{Nb}$ for change density enhancement. See Fig. 12.

The fields of cluster science and nanoscale science have in some respects grown up separately. The former nearly always involved a study of species formed from the bottom up, while in the beginning nanoscale materials most often had birth arising from the subdivision of bulk materials. Nevertheless it is becoming increasingly obvious that the two have much in common and that cluster science enables considerable new insight into the fundamental properties and behavior of matter of small size. Cluster science offers many advantages in that as they grow, they approach the properties of a surface, and ones can often be produced that model various surface sites and defects; they are reproducible in character which is frequently not the case for bulk catalysts. Small clusters are amenable to theoretical treatment, allowing comparison with experimental findings for more in depth interpretation of properties; the influence of charge density can be determined since clusters can usually be produced in any of the three states: cations, anions and neutrals. Considering the many recent findings in the field reveals that catalytic defect centers most often have either excess or in some cases depleted charge density. Hence studies of charged clusters are especially relevant.

A regime of particular interest is one where each atom counts, giving rise to materials (including catalysts) with differing properties and reactivity. The most exciting prospect is one in which material properties can be tailored to display valuable catalytic properties. Adopting selected combinations of elements to produce complex molecules and assemblies, that produce both compounds which mimic individual elements and also give rise to species of multifunctionality, offers uncountable new prospects. Contributing to the further development of this emerging area of science provides an exciting intellectual challenge and one where gas phase cluster research offers new insights and alternate approaches.
Acknowledgments The agencies which sponsored the research that led to the advances noted in this invited perspective are gratefully acknowledged: AFOSR (Grant FA9550-10-1-0071), AFOSR MURI (Grant No. FA9550-08-1-0400); U.S. Department of the Army MURI Grant No. W911NF-06-1-0280; and U.S. Department of Energy Grant DE-FG02-92ER14258. The author sincerely thanks the many present and past students and postdocs, as well as theoretical collaborators at VCU and the Humboldt University of Berlin whose work has contributed to the findings described herein.

Open Access This article is distributed under the terms of the Creative Commons Attribution Noncommercial License which permits any noncommercial use, distribution, and reproduction in any medium, provided the original author(s) and source are credited.

\section{References}

1. Basic research needs: catalysis for energy, Report from the U.S. Department of Energy, basic energy sciences workshop, 6-8 Aug 2007

2. Somorjai GA, Contereras AM, Montano M, Rioux RM (2006) Clusters, surfaces and catalysis. Proc Natl Acad Sci USA 103(28): 10577-10583

3. Somorjai GA, Park JY (2008) Molecular factors of catalytic selectivity. Angew Chem Int Ed 47:9212-9228

4. Somorjai GA, Beaumont SK, Alayoglu S (2011) Determination of molecular surface structure, composition, and dynamics under reaction conditions at high pressures and at the solid-liquid interface. Angew Chem Int Ed 50:2-16

5. Rioux R (ed) (2010) Model systems in catalysis: single crystals to supported enzyme mimics. Springer, New York. ISBN 978-0387-98041-6

6. Ertl G (2008) Reactions at surfaces: from atoms to complexity. Angew Chem Int Ed 47:3524-3535

7. Johnson GE, Tyo EC, Castleman AW Jr (2008) Cluster reactivity experiments: employing mass spectrometry to investigate the molecular level details of catalytic oxidation reactions. Proc Natl Acad Sci USA 105:18108-18113

8. Johnson GE, Mitrić R, Bonačić-Koutecký V, Castleman AW Jr (2009) Clusters as model systems for investigating nanoscale oxidation catalysis. Chem Phys Lett Front Artic 475:1-9

9. Reilly NM, Johnson GE, Castleman AW Jr (2010) The reactivity of gas phase metal oxide clusters: systems for understanding the mechanisms of heterogeneous catalysts. In: Rioux RM (ed) Model systems in catalysis: from single crystals and size-selected clusters to supported enzyme mimics. Springer, New York, pp 293-317. doi:10.1007/978-0-387-98049-2_14

10. Zemski KA, Justes DR, Castleman AW Jr (2002) Studies of metal oxide clusters: elucidating reactive sites responsible for the activity of transition metal oxide catalysts. J Phys Chem 106: 6136-6148

11. Böhme DK, Schwarz H (2005) Gas-phase catalysis by atomic and cluster metal ions: the ultimate single-site catalysts. Angew Chem Int Ed 44:2336-2354

12. Schlangen M, Schwarz H (2010) Selective C-H versus $\mathrm{O}-\mathrm{H}$ bond activation of $\mathrm{CH}_{3} \mathrm{OH}$ upon electrospraying methanolic solutions of $\mathrm{MX}_{2}(\mathrm{M}-\mathrm{Fe}, \mathrm{Co}, \mathrm{Ni} ; \mathrm{X}=\mathrm{Br}, \mathrm{I})$ : a DFT study. Chem Catal Chem 2:799-802

13. Bell RC, Zemski KA, Justes DR, Castleman AW Jr (2001) Formation, structure and bond dissociation thresholds of gas-phase vanadium oxide cluster ions. J Chem Phys 114(2):798-811 
14. Bell RC, Zemski KA, Kerns KP, Deng HT, Castleman AW Jr (1998) Reactivities and collision induced dissociation of vanadium oxide cluster cations. J Phys Chem A 102:1733-1742

15. Bell RC, Castleman AW Jr (2002) Reactions of vanadium oxide cluster ions with 1,3-butadiene and isomers of butene. J Phys Chem A 106:9893-9899

16. Justes DR, Castleman AW Jr, Mitrić R, Bonačić-Koutecký V (2003) $\mathrm{V}_{2} \mathrm{O}_{5}{ }^{+}$reactions with $\mathrm{C}_{2} \mathrm{H}_{4}$ and $\mathrm{C}_{2} \mathrm{H}_{6}$ : theoretical considerations of experimental findings. Eur Phys J 24:331-334

17. Justes DR, Mitrić R, Moore NA, Bonačić-Koutecký V, Castleman AW Jr (2003) Theoretical and experimental consideration of the reactions between $\mathrm{V}_{\mathrm{x}} \mathrm{O}_{\mathrm{y}}^{+}$and ethylene. J Am Chem Soc 125: 6289-6299

18. Lin X, Nilius N, Sterrer M, Koskinen P, Hakkinen H, Freund HJ (2010) Characterizing low-coordinated atoms at the periphery of $\mathrm{MgO}$-supported $\mathrm{Au}$ islands using scanning tunneling microscopy and electronic structure calculations. Phys Rev B 81:153406

19. Freund HJ (2010) Model studies in heterogeneous catalysis. Chem Eur J 16:9384-9397

20. Lin X, Yang B, Benai HM, Myrach P, Yulikov M, Aumer A, Brown MA, Sterrer M, Bondarchuk O, Kieseritzky E, Rocker J, Risse T, Gao HJ, Nilius N, Freund HJ (2010) Charge-mediated adsorption behavior of $\mathrm{CO}$ on $\mathrm{MgO}$-supported Au clusters. J Am Chem Soc 132:7745-7749

21. Freund HJ, Pacchioni G (2008) Oxide ultra-thin films on metals: new materials for the design of supported metal catalysts. Chem Soc Rev 37:2224-2242

22. Simic Milosevic V, Heyde M, Loin X, Konig T, Rust HP, Sterrer M, Risse T, Nilius N, Freund HJ, Giordano L, Pacchioni G (2008) Charge-induced formation of linear $\mathrm{Au}$ clusters on thin $\mathrm{MgO}$ films: scanning tunneling microscopy and density-functional theory study. Phys Rev B 78:235429

23. Vaida ME, Bernhardt TM, Barth C, Esch F, Heiz U, Landman U (2010) Ultrathin magnesia films as support for molecules and metal clusters: tuning reactivity by thickness and composition. Phys Status Solidi B 247:1001-1015

24. Harding C, Habibpour V, Kunz S, Farnbacher ANS, Heiz U, Yoon B, Landman U (2009) Control and manipulation of gold nanocatalysis: effects of metal oxide support thickness and composition. J Am Chem Soc 131:538-548

25. Yoon B, Hakinen H, Landman U, Worz AS, Antonietti JM, Abbet S, Judai K, Heiz U (2005) Charging effects on bonding and catalyzed oxidation of $\mathrm{CO}$ on $\mathrm{Au}-8$ clusters on $\mathrm{MgO}$. Science 307:403-407

26. Sanchez A, Abbet S, Heiz U, Schneider WD, Hakkinen H, Barnett RN, Landman U (1999) When gold is not noble: nanoscale gold catalyst. J Phys Chem A 103:9573-9578

27. Yoon B, Landman U (2008) Electric field control of structure, dimensionality, and reactivity of gold nanoclusters on metalsupported MgO films. Phys Rev Lett 100:056102

28. König T, Simon GH, Rust H-P, Pacchioni G, Heyde M, Freund $\mathrm{HJ}$ (2009) Measuring the charge state of point defects on $\mathrm{MgO} /$ $\mathrm{Ag}(001)$. J Am Chem Soc 131(48):17544-17545

29. Lang SM, Bernhardt TM, Barnett RN, Landman U (2010) Methane activation and catalytic ethylene formation on free $\mathrm{Au}_{2}{ }^{+}$. Angew Chem Int Ed 49:980-983

30. Bezen MCI, Breitkopf C, El Kolli N, Krafft JM, Louis C, Lercher JA (2011) Selective modification of the acid-base properties of ceria by supported Au. Chem Eur J 17:7095-7104

31. Bendetti S, Nilius N, Myrach P, Valenti I, Freund HJ, Valeri S (2011) Spontaneous oxidation of $\mathrm{Mg}$ atoms at defect sites in an MgO surface. J Phys Chem C 115(9):3684-3687

32. Preda G, Migani A, Neyman KM, Bormley ST, Illas F, Pacchioni G (2011) Formation of superoxide anions on ceria nanoparticles by interaction of molecular oxygen with $\mathrm{Ce}^{3+}$ sites. J Phys Chem C 115(13):5817-5822
33. Giordano L, Pacchioni G, Goniakowski J, Nilius N, Rienks EDL, Freund HJ (2008) Charging of metal adatoms on ultrathin oxide films: Au and Pd on FeO/Pt(111). Phys Rev Lett 101(2):026102$1-026102-4$

34. Sterrer M, Risse T, Pozzoni UM, Giordano L, Heyde M, Rust HP, Pacchioni G, Freund HJ (2007) Control of the charge state of metal atoms on thin $\mathrm{MgO}$ films. Phys Rev Lett 98(9):0961071-096107-4

35. Zhao YX, Yuan JY, Ding XL, He SG, Zheng WJ (2011) Electronic structure and reactivity of a biradical clusters: $\mathrm{Sc}_{3} \mathrm{O}_{6}{ }^{-}$. Phys Chem Chem Phys 13:10084-10090

36. Davis RJ (2003) All that glitters is not $\mathrm{Au}^{0}$. Science 301:926-927

37. Bell RC, Zemski KA, Castleman AW Jr (1998) Gas phase chemistry of vanadium oxide cluster cations. 1. Reactions with $\mathrm{C}_{2} \mathrm{~F}_{6}$ and $\mathrm{CH}_{3}-\mathrm{CF}_{3}$. J Phys Chem 102:8293-8299

38. Bell RC, Zemski KA, Castleman AW Jr (1999) Gas phase chemistry of vanadium oxide cluster cations. 2. Reactions with $\mathrm{CH}_{2} \mathrm{~F}_{2}$. J Phys Chem 103:2992-2998

39. Zemski KA, Bell RC, Castleman AW Jr (1999) Reactivities of tantalum oxide cluster cations with unsaturated hydrocarbons. Int J Mass Spectrom 184:119-128

40. Bell RC, Zemski KA, Castleman AW Jr (1999) Gas phase chemistry of vanadium oxide cluster cations. 3. Reactions with $\mathrm{CCl}_{4}$. J Phys Chem 103:1585-1591

41. Bell RC, Zemski KA, Castleman AW (1999) Size specific reactivities of vanadium oxide cluster cations. J Clust Sci 10: 509-524

42. Zemski KA, Bell RC, Castleman AW Jr (2000) Reactions of tantalum oxide cluster cations with 1-butene, 1,3-butadiene, and benzene. J Phys Chem A 104:5732-5741

43. Zemski KA, Bell RC, Justes DR, Castleman AW Jr (2001) A brief summary of reactions of Group V transition metal oxide cluster ions with butane. In: Campbell EEB, Larsson M (eds) The physics and chemistry of clusters: proceedings of Nobel Symposium 117. World Scientific, Singapore, pp 290-291

44. Zemski K, Justes D, Bell R, Castleman AW Jr (2001) Reactions of niobium and tantalum oxide cluster cations and anions with $n$ butane. J Phys Chem 105:4410-4417

45. Zemski KA, Justes D, Castleman AW Jr (2001) Reactions of Group V transition metal oxide cluster ions with ethane and ethylene. J Phys Chem A 105:10237-10245

46. Moore NA, Mitrić R, Justes DR, Bonačić-Koutecký V, Castleman AW Jr (2006) A kinetic analysis of the reaction between $\left(\mathrm{V}_{2} \mathrm{O}_{5}\right)_{\mathrm{n}}=1,2^{+}$and ethylene. J Phys Chem B 110:30153022

47. Reilly NM, Reveles JU, Johnson GE, Khanna SN, Castleman AW $\mathrm{Jr}$ (2007) Influence of charge state on the reaction of $\mathrm{FeO}_{3}^{ \pm}$with carbon monoxide. Chem Phys Lett 435:295-300

48. Reilly NM, Reveles JU, Johnson GE, Khanna SN, Castleman AW Jr (2007) Experimental and theoretical study of the structure and reactivity of $\mathrm{Fe}_{1-2} \mathrm{O}_{\leq 6}^{-}$clusters with $\mathrm{CO}$. J Phys Chem A 111:4158-4166

49. Reilly NM, Reveles JU, Johnson GE, del Campo JM, Khanna SN, Köster AM, Castleman AW (2007) Experimental and theoretical study of the structure and reactivity of $\mathrm{Fe}_{1-} \mathrm{O}_{1-5}^{+}$with CO. J Phys Chem C 111:19086-19097

50. Johnson GE, Reilly NM, Castleman AW Jr (2009) Effect of charge state and stoichiometry on the structure and reactivity of nickel oxide clusters with CO. IJMS 280:93-100

51. Johnson GE, Reveles JU, Reilly NM, Tyo EC, Khanna SN, Castleman AW Jr (2008) Influence of stoichiometry and charge state on the structure and reactivity of cobalt oxide clusters with CO. J Phys Chem A 112:11330-11340

52. Johnson GE, Reveles JU, Khanna SN, Castleman AW Jr (2010) Reactivity trends in the oxidation of $\mathrm{CO}$ by anionic transition metal oxide clusters. J Phys Chem 114:5438-5446 
53. Tyo EC, Nößler M, Mitrić R, Bonačić-Koutecký V, Castleman AW Jr (2011) Reactivity of stoichiometric titanium oxide cations. Phys Chem Chem Phys 13:4243-4249

54. Justes DR, Moore NA, Castleman AW Jr (2004) Reactions of vanadium and niobium oxides with methanol. J Phys Chem B 108:3855-3862

55. Kimble ML, Justes DR, Moore NA, Castleman AW Jr (2005) Elucidating mechanistic details of catalytic reactions utilizing gas phase clusters. In: Jena P, Khanna SN, Rao BK (eds) Clusters and nano-assemblies, physical and biological systems, ISCANA proceedings. World Scientific, Singapore, pp 127-134. ISBN 981-256-331-8

56. Johnson GE, Tyo EC, Castleman AW Jr, Mitrić R, Nößler M, Bonačić-Koutecký V (2009) Influence of charge state on catalytic oxidation reactions at metal oxide clusters containing radical oxygen centers. J Am Chem Soc 131:5460-5470

57. Johnson GE, Tyo EC, Castleman AW Jr, Mitrić R, BonačićKoutecký V (2008) Stoichiometric zirconium oxide cations as potential building blocks for cluster assembled catalysts. J Am Chem Soc 130:13912-13920

58. Haruta M (2001) Size- and support-dependency in the catalysis of noble metals: gold as a typical example. In: Campbell EEB, Larsson M (eds) Proceedings of Nobel symposium 117, the physical and chemistry of clusters. World Scientific, Singapore. ISBN 981-02-4529-7

59. Heiz U, Landman U (2006) Nanocatalysis. Springer, New York

60. Kimble ML, Moore NA, Castleman AW Jr, Bürgel C, Mitrić R, Bonačić-Koutecký V (2007) Reactivity of anionic gold oxide clusters towards CO: experiment and theory. Eur Phys J D 43: 205-208

61. Johnson GE, Tyo EC, Castleman AW Jr (2008) Gas-phase reactivity of gold oxide cluster cations with CO. J Phys Chem 112:9730-9736

62. Kimble ML, Castleman AW Jr, Mitrić R, Bürgel C, BonačićKoutecký V (2004) Reactivity of atomic gold anions toward oxygen and the oxidation of CO: experiment and theory. J Am Chem Soc 126:2526-2535

63. Kimble ML, Castleman AW Jr (2003) Probing the oxidation of carbon monoxide utilizing $\mathrm{Au}_{\mathrm{n}}^{-}$. Proceedings at the gold 2003: new industrial applications for gold conference, Vancouver, Canada, 28 Sep-1 Oct 2003
64. Kimble ML, Castleman AW Jr (2004) Gas-phase studies of $\mathrm{Au}_{n} \mathrm{O}_{m}^{+}$for the oxidation of carbon monoxide (also contributed to the foreword). Int J Mass Spectrom 233:99-101

65. Reilly NM, Johnson GE, Kimble ML, Castleman AW Jr, Bürge C, Mitrić R, Bonačić-Koutecký V (2008) Influence of charge state on the mechanism of CO oxidation on gold cluster. J Am Chem Soc 130:1694-1698

66. Kimble M, Castleman AW Jr, Bürgel C, Bonačić-Koutecký V (2006) Interactions of $\mathrm{CO}$ with $\mathrm{Au}_{n} \mathrm{O}_{m}^{-}(\mathrm{N} \geq 4)$. Int $\mathrm{J}$ Mass Spectrom 254:163-167

67. Kimble ML, Moore NA, Johnson GE, Castleman AW Jr, Bürgel C, Mitrić R, Bonačić-Koutecký V (2006) Joint experimental and theoretical investigations of the reactivity of $\mathrm{Au}_{2} \mathrm{O}_{\mathrm{n}}^{-}$and $\mathrm{Au}_{3} \mathrm{O}_{\mathrm{n}}^{-}$ $(\mathrm{n}=1-5)$ with carbon monoxide. J Chem Phys 125:204311

68. Mulliken RS (1932) The interpretation of band spectra Part III. Electron quantum numbers and states of molecules and their atoms. Rev Mod Phys 4:1-86

69. Leuchtner RE, Harms AC, Castleman AW Jr (1989) Thermal metal cluster anion reactions: behavior of aluminum clusters with oxygen. J Chem Phys 91:2753-2754

70. Castleman AW Jr, Khanna SN (2009) Clusters, superatoms and building blocks of new materials. J Phys Chem 113:2664-2675

71. Castleman AW Jr (2011) From elements to clusters: the periodic table revisited. Phys Chem Lett Perspect 2:1062-1069

72. http://goldbook.iupac.org/I03276.html

73. Levy RB, Boudart M (1973) Platinum-like behavior of tungsten carbide in surface catalysis. Science 181:547-549

74. Peppernick SJ, Gunaratne KDD, Castleman AW Jr (2010) Towards comprehending the superatomic state of matter. Chem Phys Lett 489:1-11

75. Peppernick SJ, Gunaratne KD, Castleman AW Jr (2010) Superatom spectroscopy and the electronic state correlation between elements and isoelectronic molecular counterparts. Proc Natl Acad Sci USA 107:975-980

76. Tyo EC, Castleman AW, Reber AC, Khanna SN (2011) Analogous reactivity of $\mathrm{Pd}^{+}$and $\mathrm{ZrO}^{+}$: comparing the reactivity with small hydrocarbons. J Phys Chem C. doi:10.1021/jp203740n

77. Nößler M, Mitrić R, Bonačić-Koutecký V, Johnson GE, Tyo EC, Castleman AW Jr (2010) Generation of radical centers in binary neutral metal oxide clusters for catalytic oxidation reactions. Angew Chem Int Ed 49:407 